\title{
Review of the Literature on Crisis Management in Tourism
}

\author{
Jianchun Yang ${ }^{1}$ Wenting $\mathrm{Li}^{1,{ }^{*}}$ Hongming Wei ${ }^{1}$ \\ ${ }^{1}$ Guizhou University of Finance and Economics, Guizhou, China \\ *Corresponding author. Email: $1752789072 @ q q . c o m$
}

\begin{abstract}
The outbreak of the epidemic in 2020 has had a huge impact on the global tourism industry. Tourism crisis management has attracted academic attention. This paper sorts out the research results of domestic and foreign scholars on tourism crisis management, it analyses the development process, research content and research methods of tourism crisis management in domestic and foreign. In this paper, the research status of tourism crisis management in domestic and foreign mainly focused on tourism crisis manifestation, crisis impact, crisis awareness, crisis management response, etc. The research on tourism crisis management in China lags behind that abroad. This paper looks forward to follow-up research on this basis, hoping to provide reference for future related research.
\end{abstract}

Keywords: Tourism, Crisis Management, Literature research, Research review.

\section{INTRODUCTION}

The COVID-19 epidemic that occurred at the end of 2019 had a huge impact on my country's national economy and social development. The tourism industry is the hardest hit area. Most tourist attractions in the country are closed, and all tourism performing arts are suspended. The crisis of stagnation in the tourism industry triggered by the COVID-19 epidemic has severely plagued tourism companies, governments and researchers [1]. On the one hand, Irwin (2020) proposed that under the current pattern of mass media and Internet globalization, the COVID-19 pandemic may trigger a lasting change in tourism market behavior, which may fundamentally change travel patterns. On the other hand, Novelli (2018) proposed that after specific crises including outbreaks in the past, the tourism industry usually rebounds, which shows that the tourism industry has obvious resilience in alleviating the sudden collapse of demand or supply. Just as the tourism and travel peaks that appeared during the 11th minor holiday in the second half of 2020 have demonstrated the strong momentum of the domestic tourism industry's recovery, my country's tourism industry has ushered in a post-epidemic era. At this time, discussing the mechanism of the crisis triggered by the COVID-19 epidemic affecting the tourism industry and the economy and society, and how the tourism industry and the government respond to such crises are currently a key concern and a topic that needs to be solved urgently by the academic community and the industry.

Therefore, this article systematically sorts out relevant domestic and foreign literature, clarifies the research context and framework of tourism crisis management, Understand the aspects contained in previous studies on tourism crisis management and what are missing, in order to help the tourism industry improve the level of crisis management and provide theoretical guidance for the practice of tourism crisis management.

\section{LITERATURE REVIEW OF TOURISM CRISIS RESEARCH}

Domestic documents are "advanced search" through the journal category in CNKI, this paper selects the time span from 2000 to August 2020, the search term is "tourism crisis", and two journal sources of Peking University core and CSSCI are selected, and a total of 98 relevant documents have been retrieved. Foreign documents were "advanced search" through journals in the Web of Science core database. The time span from 1980 to October 2020 was selected. The search term was "tourism crisis". A total of 224 related documents were retrieved, and the domestic Analysis of foreign literature (Figure 1 and Figure 2). 


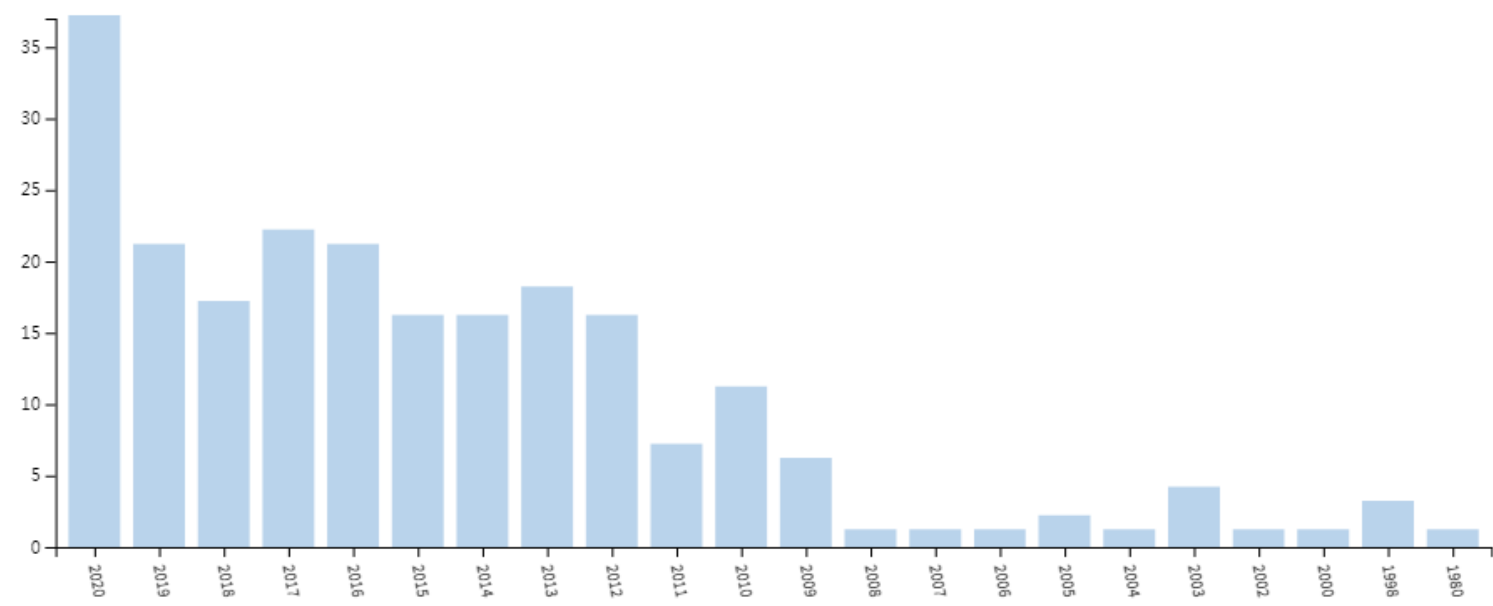

Figure 1 Distribution map of the number of domestic tourism crisis documents over the years.

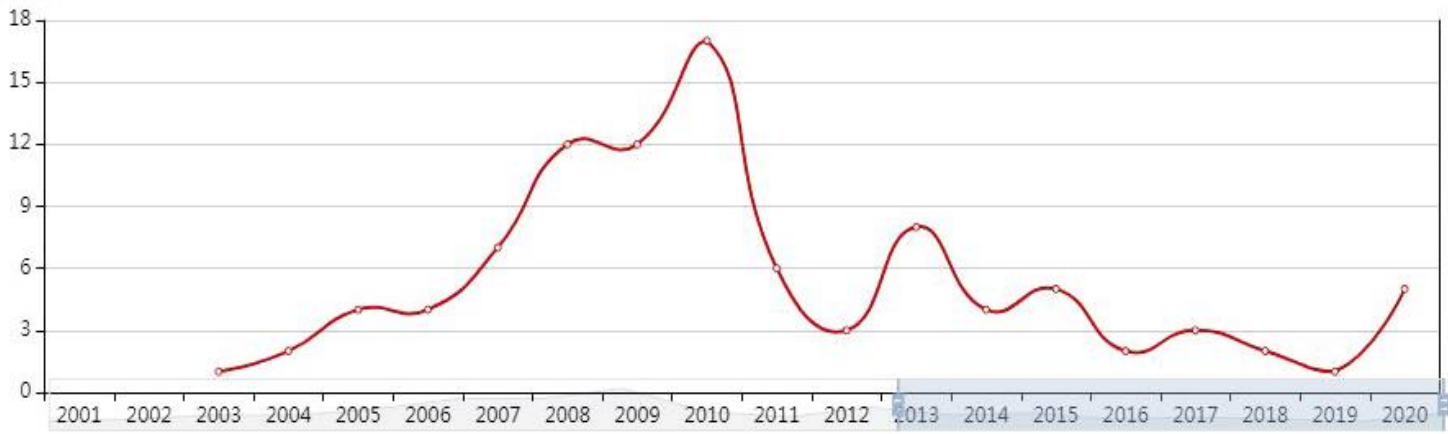

Figure 2 Distribution map of the number of foreign tourism crisis documents over the years.

It can be seen from the figure that the study of foreign tourism crisis is much earlier than that of domestic. Foreign research on the tourism crisis began in 1974 , and then increased year by year since 2008 , and the literature has increased sharply in 2020.The domestic related research began in Huang Jin's "On the Establishment of Tourism Crisis Management Mechanism" in 2003, which discussed the tourism crisis and its impact in the SARS environment, and proposed a tourism crisis management plan and the stages of tourism management. And since the SARS in 2003, the number of research documents has increased sharply, reaching the highest value in 2010, and then decreasing year by year until the outbreak of COVID-19 in 2020 began to increase again.

\section{RESEARCH CONTENTS OF TOURISM CRISIS MANAGEMENT}

Tourism crisis management is defined as "the wide-ranging efforts of various organizations to understand and prevent crises and effectively manage the crises that occur, taking into account every step of the planning activities and the interests of their stakeholders"[2]. It has increasingly become an important research field in tourism management. After the SARS incident in the 21 st century, crisis management in the tourism industry has gradually become the focus of research by domestic scholars. The current research on crisis management in the tourism industry mainly focuses on the following aspects:

\subsection{Research on the Theory of Tourism Crisis Management}

Foreign research on tourism crisis originated from the annual meeting of the Travel Research Association in 1974, and for the first time related research on crisis management was introduced. Foreign scholars have focused on the participants in the tourism crisis and the construction of the crisis management system. It mainly includes the classification of tourism crisis (Lei Shibiao, 2019), the basic framework of crisis management [3], and the construction of tourism crisis management system. The domestic academic circles' research on the definition of tourism crisis and tourism crisis management [4], tourism characteristics (Zhang Yun, 2013), and research on tourism safety sensing [5]. Relatively more. Although the domestic and foreign academic circles have not yet reached a consensus on the definition of the concept, they agree that the tourism 
crisis will inevitably lead to a sharp decline in tourism demand in a short period of time.

\subsection{Research on the Forms of Tourism Crisis}

The emergence of Covid-19 caused a large-scale suspension of international travel, further illustrating the fragility and instability of the tourism industry. There are many manifestations of tourism crises, and a correct understanding of the manifestations of crises is a prerequisite for targeted tourism crisis management. Foreign studies on the manifestations of tourism crises mainly include tsunamis (Ghaderi et al., 2013), earthquakes, terrorist activities (Samitas et al., 2018), economic and financial crises [6], political conflicts and instability (Seraphin et al., 2019), natural disasters and extreme climates (Dorota Rucinska, 2014) and public health and safety issues (Fotiadis et al., 2014) and other aspects of case studies. However, domestic scholars are more detailed in the research and classification of the forms of tourism crisis. Sun. (2008) classified tourism crises based on the formation of tourism behavior space [7]. Zhang.(2010) categorizes tourism crises according to the factors forming tourism crises.

\subsection{Research on the Impact of Tourism Crisis}

The impact of tourism crises on the tourism industry has always been the focus of research circles at home and abroad, focusing on the impact of specific specific crisis events on the tourism industry and destinations. The research is mainly conducted from two aspects: qualitative analysis and quantitative analysis. In terms of qualitative analysis, domestic and foreign scholars mainly analyze the impact of the overall or partial major crisis on the tourism industry. Mainly include unrest (Zulafqar Ahmed, 2019), economic storms (Sio-Chong U, etc., 2020), natural disasters (Dorota Rucinska, 2014), public health incidents (Ralf Buckley, 2020), terrorist activities [8]. And the impact of various major crisis events on the tourism industry. In terms of quantitative research, scholars at home and abroad focus on data analysis of specific crisis events and use econometric models to estimate their impact on the tourism industry. The most commonly used method for quantitative research on tourism crisis in China is the tourism baseline method proposed by Sun Gennian. After SARS, many scholars have used this method to conduct extensive quantitative research [9].

\subsection{Research on Tourism Crisis Management}

Tourism crisis management is a scientific management method in which tourism destinations take preventive or elimination measures against risk factors that may arise in the process of tourism development and operation, and take remedial measures after the occurrence of risks. Existing foreign research mainly explores tourism crisis management decisions by combining case destinations or crisis events. Existing research mainly includes the response to the tourism crisis caused by Ebola [10], the tourism response strategy of the terrorist incident in Bali (Gurtner Y, 2016), and the tourism response strategy of the financial crisis (Perles-Ribes JF, 2017), the tourism recovery strategy against COVID-19 (Yeh S S., 2020), and the tourism crisis response of the hotel industry (Pappas $\mathrm{N}$, 2020). Domestic scholars' research on tourism crisis management strategies mainly includes a series of tourism crisis management strategies proposed for tourism entities such as the government (Dang., 2020) and tourism companies (Wang. et al., 2013), based on the various stages of the crisis life cycle And build a tourism crisis management system model, and put forward more realistic and guiding tourism crisis management strategies.

\section{RESEARCH METHODS OF TOURISM CRISIS MANAGEMENT}

On the whole, scholars at home and abroad have used a wealth of methods in the process of studying tourism crises, involving many fields such as psychology, sociology, management, and economics. There are mainly theoretical studies, case studies and empirical studies.

\subsection{Theoretical Research}

Literature review and systematic review are the two main research methods used in conceptual research. The literature review is to review the nature of crisis and crisis management in the tourism industry by combing through the previous literature to provide reference for future related research (Mair et al., 2016). The systematic review is a study of tourism crisis management models and frameworks combined with new theories of other disciplines (Blackman.., 2018).

\subsection{Case Research}

In the study of tourism crisis, case study is one of the most important methods. Case studies mainly include: (1) Single crisis and disaster cases (ie 9-11 terrorist attack, Christchurch earthquake, political turmoil in Cyprus, The Asian financial crisis); (2) a single tourism destination or region, (3) a single tourism type or industry (cruise tourism, scenic spots and hotel industries).

\subsection{Empirical Research}

In terms of empirical research, foreign scholars mostly use questionnaire surveys, using experiments and scenario design to conduct research on the micro-level of the tourism crisis. Including online research group 
companies (Hajibaba et al., 2017); national online survey (Wang, 2012); hotel and travel agency surveys (Orchiston, 2016); tourism demand summary data and visitor arrival analysis (Okuyama, 2018) Research on different aspects of crisis events. Domestic scholars have used a series of methods such as analytic hierarchy process, background line method (Sun., 2018), spatial autocorrelation and geographic detector (Ruan. Et.al., 2020) to quantitatively analyze the macroscopic impact of tourism crisis.

\section{CONCLUSIONS AND OUTLOOK}

\subsection{Conclusion}

Since 2003, the research on tourism crisis management in China has gradually increased, and domestic theoretical and empirical research on tourism crisis management has also gradually improved. However, compared with the research abroad, it is still relatively lagging backward. Domestic scholars mainly use the overall big data or individual provinces and cities to evaluate the impact of the tourism crisis, and put forward relatively macro management suggestions. Foreign researches mainly focus on the impact of specific crisis events on tourism and tourism safety, and focus on specific crisis management strategies, which are more practical. All in all, the professional and systematic research on tourism crisis management at home and abroad is very limited, and there are still problems such as lack of theoretical innovation, insufficient research, and insufficient research methods.

\subsection{Outlook}

Crisis management has far-reaching significance to the development of tourism, and it is an important aspect of tourism management that cannot be ignored. Future research should gradually deepen the shallow research on performance characteristics, deeply analyze the mechanism of the influencing factors and the mechanism of crisis formation, so as to pave the way for more effective implementation of tourism crisis management. The COVID-19 is highly contagious, has a wide spread and lasts a long duration. In response to the tourism crisis caused by it, academia should provide more problem-solving methods, a larger theoretical basis for research, more longitudinal research and more comparative research, to help the tourism industry improve the level of crisis management, make its draw lessons from crisis management, and apply the lessons to future management to prepare for the crisis. At the same time, we should also discuss how the tourism industry can alleviate the predicament when the crisis comes. These are issues that need to be studied deeply at the moment.

\section{ACKNOWLEDGMENTS}

This work was supported by the Fund Project: General Project of the National Social Science Fund "Research on the Mechanism and Path of the High-quality Development of Ethnic Village Tourism Leading Rural Rejuvenation" (No. 20BMZ128).

\section{REFERENCES}

[1] Fotiadis A, Polyzos S, Huan T C T C. The good, the bad and the ugly on COVID-19 tourism recovery $[\mathrm{J}]$. Annals of Tourism Research, 2021, 87: 103117.

[2] Santana G. Crisis management and tourism [J]. Journal of Travel \& Tourism Marketing, 2004(15(4)), 299-321.

[3] Nizamidou C, Vouzas F, Gotzamani K. Exploring the interrelationship between quality, safety and HR within crisis management framework [J]. The TQM Journal, 2019.

[4] Zhang Yuexi., Tourism Crisis Management [M]. China Tourism Press, 2017. (In Chinese)

[5] Zhu Yao, Zou Yongguang. Study on Spatial Characteristics of Chinese Visitors to Europe [J]. Regional Research and Development, 2019, 38 (06): 74-79. (In Chinese)

[6] Sio-Chong U, So Y C. The impacts of financial and non-financial crises on tourism: Evidence from Macao and Hong Kong [J]. Tourism Management Perspectives, 2020, 33: 100628.

[7] Sun Gennian. Study on Life Cycle and Post-Evaluation of Tourism Crisis [J]. Human Geography, 2008, 23(1): 7-12. (In Chinese)

[8] Ulqinaku A, Sarial-Abi G. Tourism implications of online response to terrorism [J]. Annals of Tourism Research, 2020: 102914.

[9] Ulqinaku A, Sarial-Abi G. Tourism implications of online response to terrorism [J]. Annals of Tourism Research, 2020: 102914. (In Chinese)

[10] Novelli M, Burgess L G, Jones A, et al. 'No Ebola $\cdots$ still doomed'-The Ebola-induced tourism crisis[J]. Annals of Tourism Research, 2018, 70: 76-87. 